García Lema, Natalia Desirée.

Alumna de Doctorado, Universidad de Vigo, Departamento de dibujo (Facultad de Bella Artes Pontevedra), Grupo Dx5 Digital and Graphic art_research.

\title{
La recepción fotográfica y las imágenes especulares como virtualidades de lo real.
}

\author{
TIPO DE TRABAJO
}

Comunicación

PALABRAS CLAVE

Fragmentación, registro fotográfico, virtual, imagen especular.

KEY WORDS

Fragmentation, Photographic register, Virtual, Reflected images.

\section{RESUMEN}

La fotografía constituye un medio de registro que recorta y fragmenta la realidad. Crea una representación del mundo. Se apropia de él para luego convertirlo en imágenes. A través de ellas establece una relación mimética entre el objeto, virtualmente representado y su referente. Lo extrae de la realidad para retratarlo en un plano bidimensional. De esta manera, podemos decir que la fotografía virtualiza al transformar la realidad en imágenes.

Por otro lado, este carácter fragmentario de lo fotográfico deriva en un proceso de fragmentación, que se entiende como una ruptura entre un elemento y el conjunto al que pertenece. Los fragmentos se establecen como elementos más pequeños que el total. Parto de la obra de algunos pensadores contemporáneos como Jacques Derrida, Gilles Deleuze o Félix Guatari cuando afirman que para entender o abarcar la globalidad es necesario fragmentarla y analizar cada una de sus partes. Se trata de transmitir que la percepción (como proceso cognitivo) que captamos de la realidad no es una imagen plana y única, sino una perspectiva múltiple que suma diferentes puntos de atención.

Un antecedente que surge a principios del S.XX relacionado con esta visión polifacética lo encontramos en el Cubismo de Georges Braque y Pablo Picasso cuando vemos diferentes perspectivas que se conectan, se superponen y dialogan entre sí creando representaciones complejas. Los objetos se ven desplegados, mostrados desde diferentes ángulos, lo que nos ofrece una visión poliédrica, más completa. Si aplicamos estos parámetros a la fotografía obtendremos una nueva manera de percibir el entorno, desde un punto de vista diseminado o poliédrico.

A su vez, esta metodología de la fragmentación se focaliza en los espejos como superficies que transforman o fragmentan. Los reflejos, imágenes que despliegan, amplían o distorsionan el espacio reproducen con una fisicidad aparente y frágil el entorno que los rodea.

\section{ABSTRACT}

Photography is a way of recording that cuts out and fragments reality. It creates a world representation and appropriates it, to transform it into pictures. Through them a mimetic relationship is established between the virtual represented object and the real object, wish is taken out of the reality to photograph it in a two-dimensional plane. This way we can tell that photograph transforms reality into images.

On the other hand this photographic fragmentary quality becomes a process of fragmentation which is understood as a rupture between an element or a part of it and the whole object which it belongs to. Fragments understood as smaller 
elements from the whole object. Starting from the works of some contemporary philosophers and great thinkers as: Jacques Derrida, Gilles Deleuze or Félix Guattari, who affirm that to understand or to embrace the whole object, it is necessary to fragment and analyse each part of the whole separately. It's about transmitting the perception (as a process of cognition) that all we capture from the reality is not a flat and unique image but a many-sided perspective where different attention points are summarized.

A previous experiment related to the many-sided vision is set at the beginning of the $20^{\text {th }}$ Century in the Cubism by Georges Braque and Pablo Picasso, where we can see different perspectives, linked, superimposed and establishing a dialogue between them and at the same time, creating complex representations. Objects can be seen unfolded, shown from different points of view what offers us a perfect and complete polyhedral vision. If we apply all this to the photography we will get a new way of observing our surroundings from a spread or polyhedral points of view.

At the same time, this methodology of fragmentation is focussed on mirrors because they are surfaces that transform or fragment reality. Reflections as images that unfold, enlarge or distort the space reproduce a physical and fragile appearance the surrounding environment.

\section{CONTENIDO}

El contexto de la investigación que realizo para mi tesis doctoral se centra en la fragmentación como elemento conceptual; como una manera de percibir el entorno desde un punto de vista plural, diseminado y poliédrico. Me interesan aquellos procesos en los que la fragmentación se vincula con la imagen fotográfica. Se entiende dicho proceso de creación como una ruptura entre una parte y el todo. Omar Calabrese describe la relación entre estos dos términos como una reciprocidad, implicación, presuposición, puesto que el uno no se explica sin el otro. ${ }^{1}$ Si la acción de descomponer el todo se repite sucesivamente, lo que quedan son las partes en las que se ha dividido o de-tallado ${ }^{2}$. Puede parecer un método que aparentemente destruye, que fracciona, disemina y rompe. Sin embargo, también crea nuevas configuraciones que alteran o transforman el concepto de imagen como elemento completo. Todo ello posibilita una relectura de la información a la vez que la aparición de nuevos planteamientos y sentidos.

Los fragmentos se establecen como elementos relevantes más pequeños que el conjunto al que pertenecen. Parto de la premisa esgrimida por algunos pensadores contemporáneos como Jacques Derrida, Gilles Deleuze o Félix Guattari cuando afirman que para entender o abarcar la globalidad, es preciso fragmentarla para analizar cada una de sus partes. Si aplicamos estas premisas a la creación visual (en concreto al registro fotográfico), obtendremos que cada una de esas partes por separado pueden ensamblarse de una manera específica para, por ejemplo recomponer, una escena u objeto desde diversos puntos de vista. Se posibilita entonces una percepción activa y múltiple que se sirve de una sucesión de miradas u ojeadas lanzadas en diferentes direcciones ${ }^{3}$. La percepción (como proceso cognitivo) que captamos de la realidad no es una imagen plana y única, sino un amplio recorrido visual que ofrece una perspectiva múltiple que suma diferentes puntos de atención.

\footnotetext{
${ }^{1}$ CALABRESE, Omar: La era neobarroca. CATEDRA, Signo e imagen Madrid, 1989 p.: 84

2 "Detalle viene del francés renacentista (...) $<<$ detail $>>$, es decir cortar de. Esto presupone, por tanto, un sujeto que $<<$ corta $>>$ un objeto (...) indica la existencia de un corte de un conjunto ya desarrollado precedentemente por alguien" Ibid., p.: 86 3 HOCHBERG, Julian : "La representación de objetos y personas" En: Arte, percepción y realidad. $2^{a}$ ed. Paidós Comunicación. Barcelona, 1993 p.: 90
} 


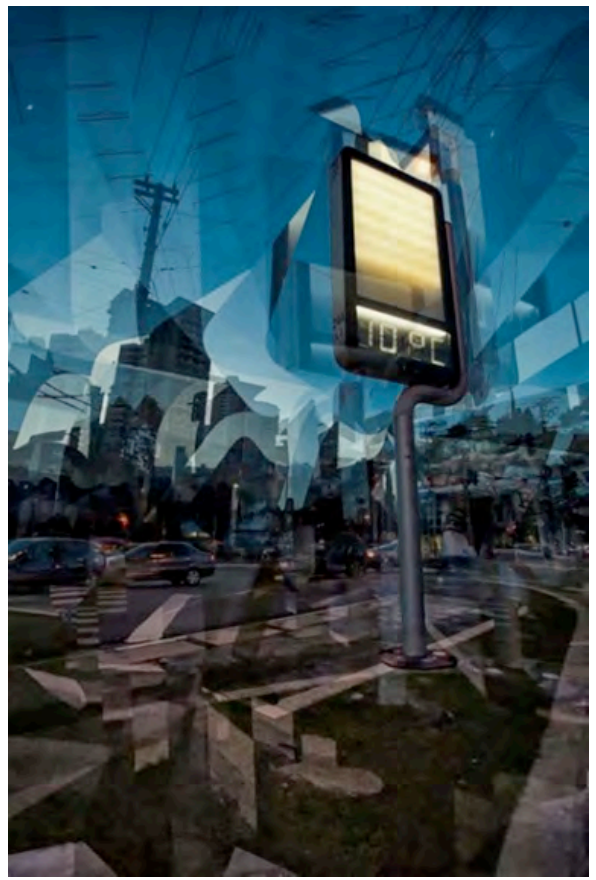

Ilustración 1 Diego Kuffer. Serie Crononauta. №5 2012

Esta concepción de lo fragmentario como una parte desprendida o un recorte se relaciona directamente con la fotografía. El acto fotográfico es en sí mismo un proceso que realiza un corte espacio-temporal (golpe del corte, "cut") de la realidad. Como expresa Philippe Dubois: "La foto aparece así (...) como una tajada, una tajada única y singular de espacio-tiempo, literalmente cortada en vivo. Huella tomada en préstamo, sustraída a una doble continuidad. Pequeño bloque de estando-ahí, pequeña porción de aquí-ahora"4 La información visual que recoge la cámara fotográfica alude a un proceso sustractivo de un instante petrificado y un espacio determinado por el encuadre y el fuera de campo. Susan Sontag también alude a la idea de fragmentación en la creación fotográfica cuando menciona: los fotógrafos descubrieron que cuanto más recortaban estrictamente la realidad aparecían formas magníficas ${ }^{5}$

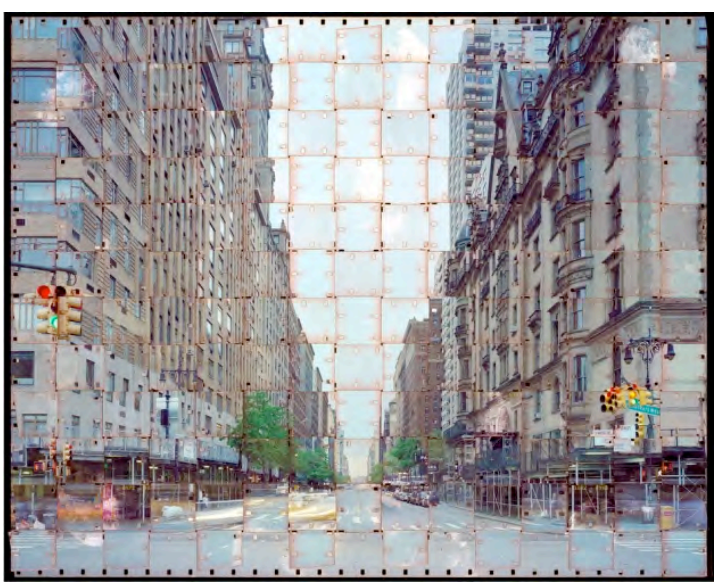

\section{Ilustración 2 Seung Hoon Park In Front of the Dakota, NY 150 cm x 120 cm 2014}

La fotografía extrae de la realidad, detiene el espacio-tiempo y fija en el instante de disparo, al mismo tiempo que crea y recoge el fragmento-imagen. La cámara se apropia del mundo tridimensional para convertirlo en imágenes o escenas, contenidas en un plano

\footnotetext{
${ }_{5}^{4}$ DUBOIS, Philippe: El acto fotográfico. De la representación a la recepción. Paidós Comunicación 20, Barcelona, 1986. p.: 141

${ }^{5}$ SONTAG, Susan: Sobre la fotografía. $5^{\text {a }}$ ed. Debolsillo. Barcelona, 2011.p.: 94
} 
bidimensional. A través de ellas establece una relación de correspondencia ${ }^{6}$ entre el objeto, virtualmente representado y su referente real. No hay duda de que la imagen hace referencia a un elemento que existe tridimensionalmente en la realidad. El componente mimético se mantiene. Si además hablamos de la captura fotográfica en términos digitales, la imagen digital es un soporte que permite todas las modificaciones en cuanto a aspectos sobre la apariencia de la imagen. Si éstas se pueden manipular por medio de programas digitales que permiten cambiar sus características, el resultado de todas estas operaciones será muy diferente al referente originario y real. Se evidencia entonces, la diferencia entre lo real (físico, material, tangible) y su representación, que al fin y al cabo es una imagen creada a partir de información virtual recogida, en este caso fotográficamente.

La naturaleza del registro fotográfico determina una transformación o reducción de las proporciones de la escena u objeto. Esto lleva a pensar que la imagen fotográfica mantiene una relación complementaria pero a la vez, contradictoria con su referente real, pues lo traduce a otros términos de la representación. Por un lado las formas y características tridimensionales de lo real se eliminan para enmarcarse en un plano bidimensional. De esta manera cualquier aspecto relativo al volumen, profundidad o tridimensionalidad desaparecen. La fotografía que obtendremos de este proceso será un archivo que haga referencia a la realidad, que luego se imprimirá en un soporte. Por otra parte, la propia técnica que hace posible la recepción fotográfica utiliza unos parámetros que reducen, comprimen y codifican aquello que se registra para crear una imagen. Y cuando las observamos, ofrecen un efecto de realidad que define Javier Marzal Felici como aquel o aquellos efectos conducentes a crear la <<impresión de realidad〉>, efectos que tratan de provocar una identificación entre la representación audiovisual y la realidad. ${ }^{7}$

Esta cualidad se asemeja a las características de la realidad virtual, cuyo funcionamiento consiste en crear una ilusión, una apariencia de realidad que permite al usuario tener la sensación de estar en un mundo diferente al real. La creación de una realidad artificial visual y táctil - a partir de la interacción/conexión de un sistema informático con un visor tridimensional y un guante acoplado ad hoc al cuerpo humano. 8

Lo virtual se establece entonces como una construcción que describe José Ramón Alcalá como un término intangible, al referirnos a una realidad cuya naturaleza nos impide tropezar físicamente con ella ${ }^{9}$. Esto significa que no tiene las propiedades características de los objetos reales como tridimensionalidad, volumen o profundidad por citar algunos rasgos que podrían definir a un objeto real. Por otra parte, esta condición de intangibilidad posee propiedades específicas que vienen determinadas por características intrínsecas de los sistemas electrónicos que las acogen y las gestionan ${ }^{10}$. En este contexto de espacios intangibles (informáticos, electrónicos) opuestos a lo háptico o material, la imagen virtual funciona como un código que debe interpretarse a través de programas o aplicaciones específicas que puedan visualizar, leer e interpretar. "...la imagen digital no es realmente una imagen, son líneas de código, un archivo que ha de ser interpretado, leído como imagen, según lo indique su "extensión"..."11 Además esta condición de intangibilidad, a pesar de parecer poco precisa subraya las infinitas posibilidades de creación, modificación o manipulación de imágenes en el entorno digital. El archivo creado en la cámara se transfiere a un sistema informático que, gracias a programas específicos (como por ejemplo Adobe Photoshop) se puede manipular, retocar o transformar por completo. Permite hacer todo tipo de modificaciones y no hay ningún paso definitivo hasta que la imagen/creación digital se imprime. Es un bucle de acciones que permiten volver atrás para corregir errores, recuperar un estado anterior de la imagen e incluso volver a partir de la imagen inicial. Cada paso se puede deshacer, lo que es una ventaja frente a otras metodologías de creación más estáticas en este sentido del proceso (como la pintura o el grabado. Una vez que se pinta el lienzo o se estampa en un papel no hay forma de volver atrás más que repetir el proceso de nuevo). La imagen no se concibe como algo definitivo hasta que se prepara para la impresión, para volver al mundo real, ahora dotada de una nueva fisicidad. Dicha imagen se imprime, en un soporte con unas medidas y una textura determinadas. El mundo tridimensional acoge este nuevo objeto como representación diferente e inédita de su referente originario. Esto se refleja en una reflexión de Juan Martín Prada que plantea:

Y si en la pantalla todo lo que aparecía era fácilmente separable, modificable por separado, en la impresión todo conforma un ente único, los datos se han sedimentado para siempre. Ahora, la imagen pasa de emitir luz a recibirla y a reflejarla. Su superficie es ya una piel a ser experimentada por el ojo. Consignada a este soporte, la imagen, antes un archivo digital, una memoria de proceso, deviene ahora archivo material, memoria de permanencia, imagen-cuerpo para el futuro. Pierde así el carácter de

\footnotetext{
${ }^{6}$ Expreso aquí relación de correspondencia por lo siguiente: La relación mimética existe. Más adelante hablaré de un entorno reflejado percibido a través de los espejos, que se distorsiona y se transforma. La fotografía que registre y capte este cambio estructural y formal no es una imagen mimética al $100 \%$. Sino que permite ciertas variaciones respecto al referente original.

${ }^{7}$ MARZAL FELICl, Javier: Cómo se lee una fotografía. Interpretaciones de la mirada. $4^{a}$ edición. Signo e Imagen. Madrid, 2011. p.: 61

${ }^{8}$ PUIG PEÑALOSA, Xavier: "La crisis de la representación en la era postmoderna. El caso de Jean Baudrillard". Ediciones Abya-Yala Quito (Ecuador) 2000. p.: 27 ISBN: 9978-04-612-7

${ }_{9}^{9}$ ALCALÁ, José Ramón: La piel de la imagen. Ensayos sobre gráfica en la cultura digital. Sendemà Editorial, Valencia, 2011 p.: 37

${ }^{10}$ Ibid., p.: 37

${ }^{11}$ MARTÍN PRADA, Juan “La condición digital de la imagen”. En Lúmen_ex, 2010. Catálogo de la 1ª edición de los Premios de Arte Digital/ Digital Art Adwards. Cáceres. Universidad de Extremadura p.: 44 <http://www.eweb.unex.es/eweb/premiosartedigital/catalogo_lumen_ex_2010.pdf>
} 
actualidad pura que tenía en la pantalla, aquel "siendo ahi", abierto siempre a cualquier modificación, para situarse ahora en la resistencia ante el tiempo. ${ }^{12}$

La pantalla del ordenador, como la de la cámara fotográfica, no es más que el principio. Son ventanas hacia el espacio intangible de lo digital que confluyen en un entorno de trabajo donde tienen lugar las transformaciones de las imágenes virtuales.

Hemos hablado de la fotografía como un medio de registro que produce virtualidades y recorta el mundo tridimensional para convertirlo en imágenes. Otro medio que funciona de manera similar generando una imagen virtual en su superficie es el espejo. "Los espejos eliminan la tridimensionalidad e invierten la imagen; algunos la empequeñecen o la agrandan; otros, la deforman, como los que producen grotescas distorsiones en ferias y parques de atracciones. Unos espejos son semitransparentes y sirven para espiar; otros son cóncavos y amplían la porosidad de nuestra piel para comprobar la perfección de una depilación o un rasurado" ${ }^{13}$ Estas características describen a los espejos como intermediarios, que además de utilizarse para observar la imagen que reflejan (que se podría interpretar como una trayectoria que empieza en el objeto/sujeto real, rebota en el espejo, creando la imagen y vuelve otra vez al objeto/sujeto real) también se usan para mirar a través ellos. Esto tiene unos fines encaminados a observar minuciosamente sin ser vistos en el otro lado. Esto es realmente significativo, puesto que en estas circunstancias se cumple que lo que hay al otro lado del espejo pertenece al mundo real. Un ejemplo son las salas de interrogatorios de una comisaría de policía. Detrás del espejo hay alguien que observa analizando conductas o situaciones, sin que el individuo que está en la sala sepa que hay alguien al otro lado. Como se aprecia, este soporte tiene usos muy diversos. Lo importante es conocer sus propiedades y las posibilidades que ofrecen para la creación de imágenes.

Los espejos constituyen modelos de reproducción que modifican, alteran o transforman los elementos de la realidad, en tanto que producen una imagen virtual. Reproducen, duplican y fragmentan. Escogen la porción de realidad que reflejan, determinada por la posición del elemento reflejado, devolviendo una imagen virtual, fragmentada y fluctuante. Modifican la percepción que tenemos del espacio real. Si hablamos de una percepción considerada como la suma de diferentes imágenes con ángulos y perspectivas distintas, el ejercicio visual se vuelve más complejo; se agudiza para descubrir todos los detalles que difieren de nuestra percepción cotidiana de la realidad. Si además aplicamos ciertas características que poseen los espejos de transformar, deformar, distorsionar o unir en un mismo plano perspectivas de diferentes lugares que se superponen como estratos, obtendremos una vista diferente; que altera nuestra percepción de la realidad, tal y como la conocemos.

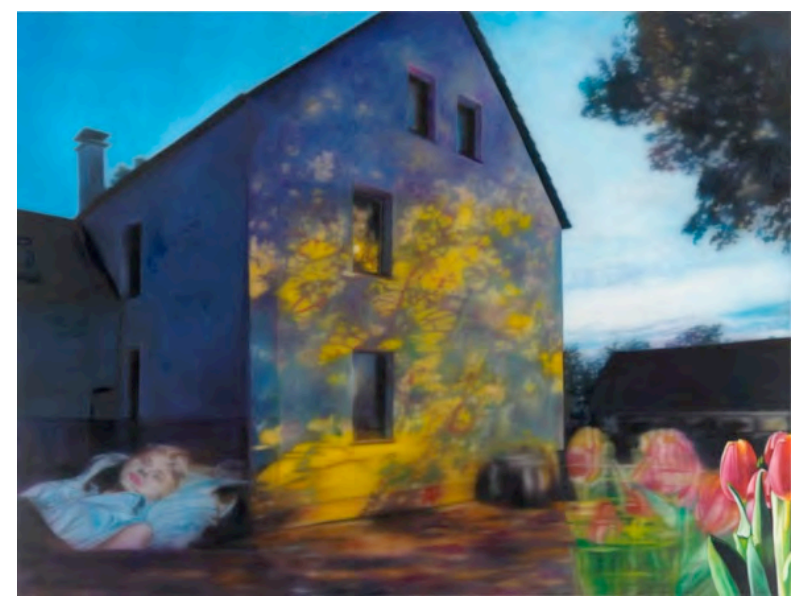

llustración 3 Karin Kneffel. Sin título. Óleo sobre lienzo. 180×240cm 2013

Las superficies de espejo reflejan el mundo sin apropiarse de él (como sí lo hace la fotografía al recortar y convertir ese fragmento en imagen fotográfica). Se sirven de una superficie bidimensional cuya capacidad es la de reflejar el entorno real transformándolo y presentándolo con una apariencia similar a la real, pero distinta. La imagen se presenta como una visión fugaz, efímera y cambiante. Constituye un plano de representación que admite nuevas configuraciones y maneras de entender lo real. Este tipo de imágenes, virtuales, no podrían darse sin la existencia de un referente, por lo que éste tiene que estar presente ${ }^{14}$. Observamos una superficie

\footnotetext{
12 Ibid., p.: 53

${ }^{13}$ FONTCUBERTA, Joan: El beso de Judas. Fotografía y verdad. $2^{\mathrm{a}}$ ed. Gustavo Gili, Barcelona, 2011 p.: 31

14 "En el espejo es necesaria la presencia de esos elementos para que las imágenes se muestren en su superficie" RODRIGUEZ CUNILL, Inmaculada: "El significado del espejo en las instalaciones y las videoinstalaciones" En: Multiplicidad y fragmentariedad en el arte contemporáneo a través de un análisis de instalaciones y videoinstalaciones. Alicante. Biblioteca virtual de Cervantes, 2003. p.: 357 ISBN: 84-688-5188-4
} 
que ya nos está devolviendo una mirada; nuestra propia mirada convertida en virtualidad. Nos analiza como si nosotros fuéramos el objeto reproducido y ella (la mirada que sale del espejo), el sujeto que pertenece al mundo real. Entonces, observamos con cierta familiaridad el entorno y también a nosotros mismos. Dice Inmaculada Rodríguez Cunill basándose en una afirmación de Umberto Eco que el hombre es un ser catóptico, es decir que tiene la experiencia del espejo. Con ello se refiere a la asunción de que lo que hay ante él (...) es una imagen, y que esta imagen depende directamente de los movimientos de su cuerpo. Se trata por tanto de la asunción de un mecanismo cuyo resultado es una imagen. ${ }^{15}$

El ser humano tiene la experiencia del mundo de las imágenes, de verse reflejado, de identificarse en ellas además de reconocer el entorno. También de construir su propia idea de realidad a través de las percepciones visuales, que en cierto modo son construcciones derivadas de su propia subjetividad. A este respecto, la fotografía ha contribuido a crear toda una imaginería que representa el mundo visual y el virtual en pequeños fragmentos. El espejo, igualmente escoge y fragmenta una parte de la realidad, aquello que se encuentra enfrente de él y lo refleja. Crea una imagen que cambia según el punto de vista y la posición del observador. Como Alicia, escrutamos y a través del espejo, buscamos las claves para descifrar esa extraña familiaridad de lo reflejado. El punto de vista se encuentra invertido, los elementos se duplican y todo parece igual. Sin embargo, lo que parece real e idéntico es una construcción especular, óptica e ilusoria, por lo tanto, también virtual que acerca otra manera de percibir la realidad.
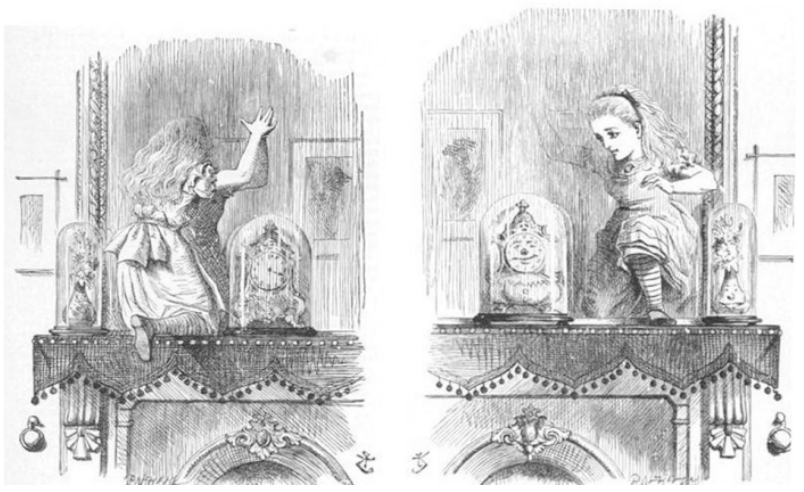

Ilustración 4 Ilustración de: A través del espejo y lo que Alicia encontró al otro lado, realizada por John Tenniel (1820-1924)

\section{FUENTES REFERENCIALES.}

ALCALÁ, José Ramón: La piel de la imagen. Ensayos sobre gráfica en la cultura digital. Sendemà Editorial. Valencia, 2011

CALABRESE, Omar: La era neobarroca. CATEDRA, Signo e imagen Madrid, 1989

DERRIDA, Jacques: La diseminación. 7ạed. Fundamentos. Madrid, 1997

DUBOIS, Philippe: El acto fotográfico. De la representación a la recepción. Paidós Comunicación 20, Barcelona, 1986

FONTCUBERTA, Joan: “Elogio del vampiro” En: El beso de Judas. Fotografía y verdad. $2^{a}{ }^{a}$ d. Gustavo Gili. Barcelona 2011 pp.: $29-40$

Karin Kneffel La ventana y el espejo. Museo de Arte Contemporáneo Gas Natural Fenosa. A Coruña 2014 (Catálogo de exposición 16/10/2014-8/02/2015) ISBN: 978-84-617-1984-6

MARZAL FELICI, Javier. Cómo se lee una fotografía. Interpretaciones de la mirada. 4a edición. Signo e Imagen. Madrid 2011

\footnotetext{
${ }^{15}$ Ibid., p.: 357
} 
MARTín PRADA, Juan “La condición digital de la imagen". En Lúmen_ex, 2010. Catálogo de la 1a edición de los Premios de Arte Digital/ Digital Art Adwards. Cáceres. Universidad de Extremadura pp.: 41-53

<http://www.eweb.unex.es/eweb/premiosartedigital/catalogo_lumen_ex_2010.pdf>

PUIG PEÑALOSA, Xavier: “La crisis de la representación en la era postmoderna. El caso de Jean Baudrillard”. Ediciones Abya-Yala Quito (Ecuador) 2000. p.: 27 ISBN: 9978-04-612-7

SONTAG, Susan: Sobre la fotografía. 5a ed. Debolsillo. Barcelona, 2011

RODRIGUEZ CUNILL, Inmaculada: “El significado del espejo en las instalaciones y las videoinstalaciones” En: Multiplicidad y

fragmentariedad en el arte contemporáneo a través de un análisis de instalaciones y videoinstalaciones. Alicante. Biblioteca virtual de Cervantes, 2003. pp.: 54-376 ISBN: 84-688-5188-4 